\title{
Post-transplantation Outcomes in Patients with PA or MMA: A Review of the Literature
}

Sufin Yap · Roshni Vara · Ana Morais

Received: February 4, 2020 / Published online: April 8, 2020

(C) The Author(s) 2020

\section{ABSTRACT}

Introduction: Liver transplantation is recognised as a treatment option for patients with propionic acidemia (PA) and those with methylmalonic acidemia (MMA) without renal impairment. In patients with MMA and moderate-to-severe renal impairment, combined liver-kidney transplantation is indicated. However, clinical experience of these transplantation options in patients with PA and MMA remains limited and fragmented. We undertook an overview of post-transplantation outcomes in patients with PA and MMA using the current available evidence.

Methods: A literature search identified publications on the use of transplantation in patients with PA and MMA. Publications were considered if they presented adequate demographic and outcome data from patients with PA or

Digital features To view digital features for this article go to https://doi.org/10.6084/m9.figshare.11994477.

S. Yap $(\bowtie)$

Department of Inherited Metabolic Diseases,

Sheffield Children's Hospital, Sheffield, UK

e-mail: sufin.yap@nhs.net

R. Vara

Evelina London Children's Hospital, London, UK

A. Morais

Child Nutrition and Metabolic Diseases Unit,

University Hospital La Paz, Madrid, Spain
MMA. Publications that did not report any specific outcomes for patients or provided insufficient data were excluded.

Results: Seventy publications were identified of which 38 were full papers. A total of 373 patients underwent liver/kidney/combined liver-kidney transplantation for PA or MMA. The most typical reason for transplantation was recurrent metabolic decompensation. A total of 27 post-transplant deaths were reported in patients with PA $[14.0 \%(27 / 194)]$. For patients with MMA, 18 post-transplant deaths were reported [11\% (18/167)]. A total of 62 complications were reported in 115 patients with PA (54\%) with cardiomyopathy $(n=12)$, hepatic arterial thrombosis (HAT; $n=14$ ) and viral infections $(n=12)$ being the most commonly reported. A total of 52 complications were reported in 106 patients with MMA (49\%) with viral infections $(n=14)$ and renal failure/impairment $(n=10)$ being the most commonly reported.

Conclusions: Liver transplantation and combined liver-kidney transplantation appears to benefit some patients with PA or MMA, respectively, but this approach does not provide complete correction of the metabolic defect and some patients remain at risk from disease-related and transplantation-related complications, including death. Thus, all treatment avenues should be exhausted before consideration of organ transplantation and the benefits of this approach must be weighed against the 
risk of perioperative complications on an individual basis.

Keywords: Kidney transplantation; Liver transplantation; Methylmalonic acidemia; Morbidity; Mortality; Propionic acidemia

\section{Key Summary Points}

A literature review was performed to ascertain the outcomes associated with liver and or kidney transplantation in patients with propionic acidemia (PA) or methylmalonic acidemia (MMA).

Thirty-eight papers and 32 abstracts were identified, totalling 373 patients.

Transplantation improved outcome in some patients with PA and MMA, but was also associated with appreciable mortality (14\% PA, 11\% MMA) and complications including cardiomyopathy, hepatic arterial thrombosis, renal failure/ impairment, and viral infections.

While transplantation appears to be of some benefit in a subset of patients with PA/MMA, this approach does not provide a metabolic cure and patients remain at risk from disease-related and transplantation-related complications.

All treatment avenues should ideally be exhausted for PA/MMA before selecting transplantation.

\section{INTRODUCTION}

Propionic acidemia (PA) and methylmalonic acidemia (MMA) are rare inborn errors of metabolism presenting in infancy with episodes of metabolic acidosis that can lead to early mortality and significant morbidity [1-3]. Both PA and MMA are characterised by the accumulation of propionic acid and/or methylmalonic acid in plasma, urine, and other body fluids, due to defects in the enzymes propionyl-CoA carboxylase and methylmalonyl-CoA mutase, respectively.

Patients with PA and/or MMA typically present shortly after birth with acute deterioration, metabolic acidosis, and hyperammonaemia leading to either severe intellectual disabilities or death [1]. For these patients with 'classical' PA and MMA, dietary restriction (a low-protein, high-energy diet) together with oral medication (typically carnitine) has remained the core therapy for decades. However, despite intensive medical efforts, frequent episodes of metabolic decompensation occur with inevitable complications [1].

Solid-organ transplantation, such as single liver or kidney transplantation, or combined liver-kidney transplantation, has become an effective alternative treatment for metabolic disease in recent decades [1]. The role of liver, kidney, or combined liver-kidney transplantation in patients with PA/MMA is currently evolving and, while not considered 'curative', is typically undertaken as an 'enzyme replacement therapy' [4]. However, any decision to carry out a transplantation is a complicated one which requires a comprehensive understanding of the underlying disease, the risks and benefits of transplantation, and current therapeutic alternatives [5]. Furthermore, clinical experience of transplantation in PA and MMA remains both limited and fragmented due to the low prevalence of these diseases $[4,6]$.

The purpose of this review is to provide an overview of post-transplantation outcomes in patients with PA and MMA.

\section{METHODS}

A literature search was undertaken on 10 April 2019 to identify suitable papers for inclusion in the present review. The literature search tools used were PubMed, Embase and Biosys. The search string was [(propionic OR methylmalonic) AND acidemia*] AND [(transplant OR transplantation) AND aciduria*]. No date limitations were applied. Suitable references for inclusion included abstracts and full papers, clinical studies, case studies, and retrospective 
analyses of patients with PA and/or MMA. Any references which included patients with $\mathrm{PA}$ or MMA as part of a pooled population of patients with inherited metabolic disorders but did not report any specific outcomes for these patients were excluded, as were abstracts providing insufficient data. Given the methodology used, this review was undertaken to assess any trends arising from the use of liver/kidney/combined liver-kidney transplantation in patients with PA/MMA.

This article is based on previously conducted studies and does not contain any studies with human participants or animals performed by any of the authors.

\section{RESULTS}

\section{Patient Demographics and Follow-up}

Seventy suitable references (retrospective analyses and case studies) were identified, 32 of which were meeting abstracts. A summary of transplantation type and median patient age taken from these references is shown in Table 1. A total of 195 and 167 patients underwent liver/ kidney/combined liver-kidney transplantation for PA and MMA, respectively (a total of 373 transplantations). In addition, a total of nine and two retransplantations were required in patients with PA and MMA, respectively. Single organ liver transplantation was performed more commonly in both PA and MMA (total $n=307$, PA $n=193$; MMA $n=114)$, when compared with kidney (PA $n=2$; MMA $n=21$ ) or combined liver-kidney transplantation (PA $n=0$; MMA $n=32$ ) (retransplantations not included). Median age at transplantation ranged from 0.25 to 42 years in patients with PA and from 0.4 to 28.0 years in patients with MMA. The most typical reason for any type of transplantation in patients with PA and MMA was recurrent metabolic decompensation. Follow-up data to show outcomes by type of transplantation were available for all PA ( $n=195$; available follow-up range $0-22$ years) and MMA $(n=167$; range 0.04-16 years) patients, although specific timings of follow-up were not always provided.

Of the 70 references identified, 38 were full papers which contained sufficient patient information, both pre-operatively and posttransplantation, along with a suitable follow-up duration to enable a more detailed overview. A summary of key findings from these references is shown in Tables 2 and 3. Available data from the identified abstracts were limited and are summarised in the "Appendix".

Table 1 Overall characteristics of reviewed patients

\begin{tabular}{lll}
\hline Characteristic & PA & MMA \\
\hline Liver transplantation & 193 & 114 \\
Kidney transplantation & $2^{\mathrm{a}}$ & 21 \\
Combined transplantation & 0 & 32 \\
Retransplantation & 9 & 2 \\
Total transplantation & 204 & 169 \\
Median age at transplant, range, years ${ }^{\mathrm{b}}$ & $0.25-42.0$ & $0.4-28.0$ \\
Mortality & $27 / 195(14 \%)$ & $18 / 167(11 \%)$ \\
Complications & $62 / 115(54 \%)$ & $52 / 106(49 \%)$ \\
\hline $\begin{array}{l}M A \text { methylmalonic acidemia, } P A \text { propionic acidemia } \\
\text { a One patient had a liver transplantation followed approximately } 3 \text { years later by a kidney transplant }[7]\end{array}$ \\
$\begin{array}{l}\text { b Based on available data } \\
\text { c Publications not reporting complications and their associated patient numbers were excluded }\end{array}$
\end{tabular}




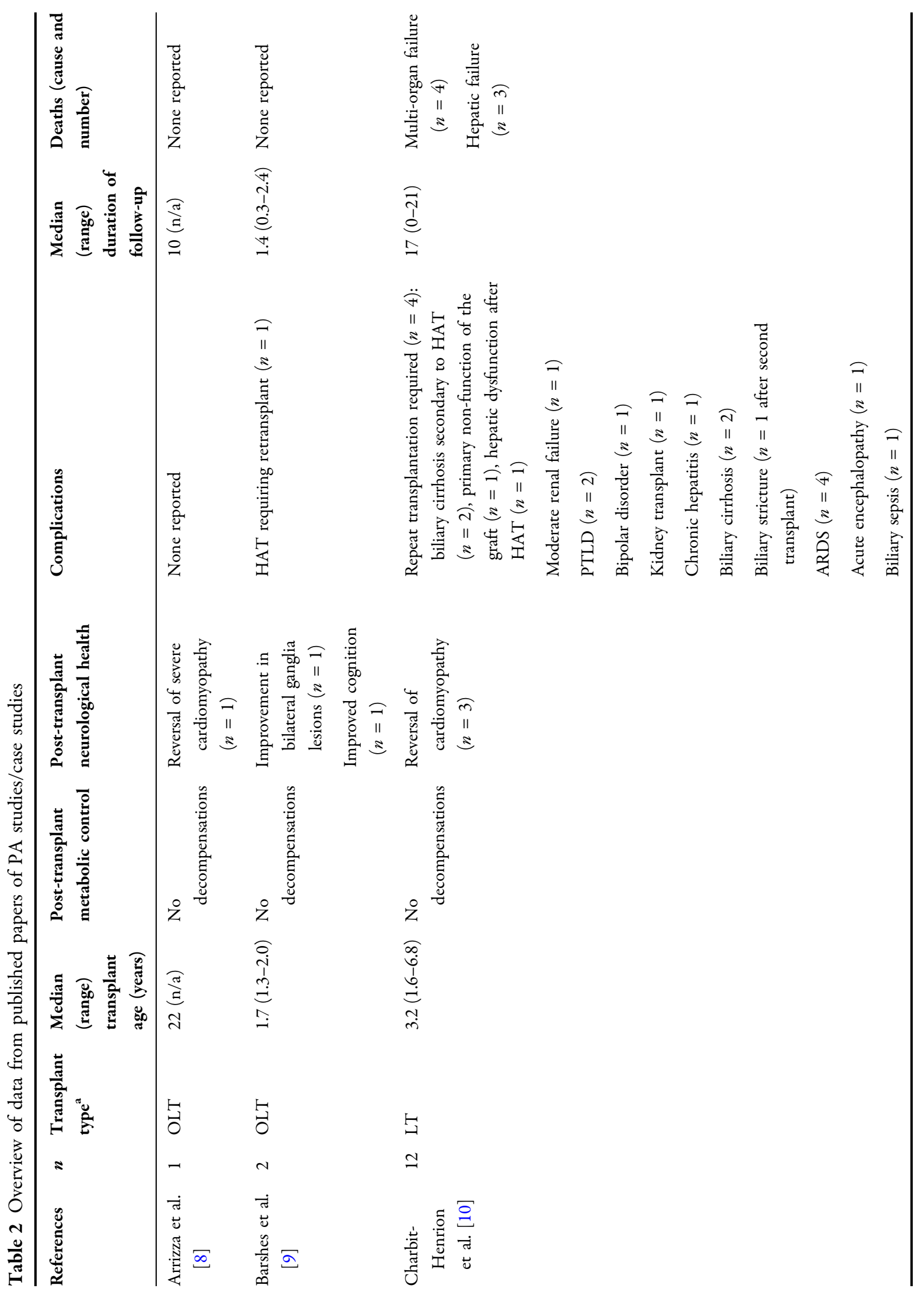




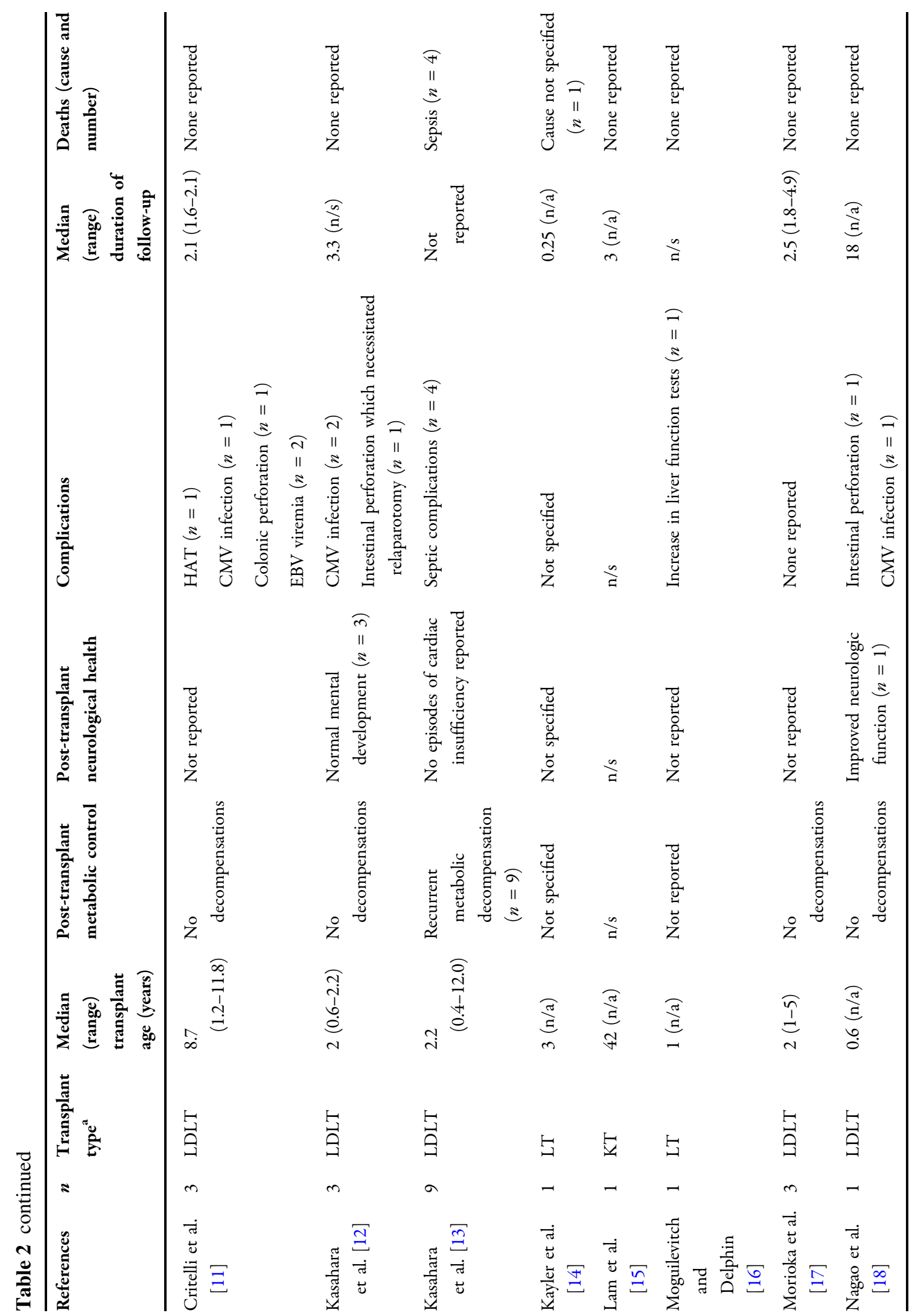




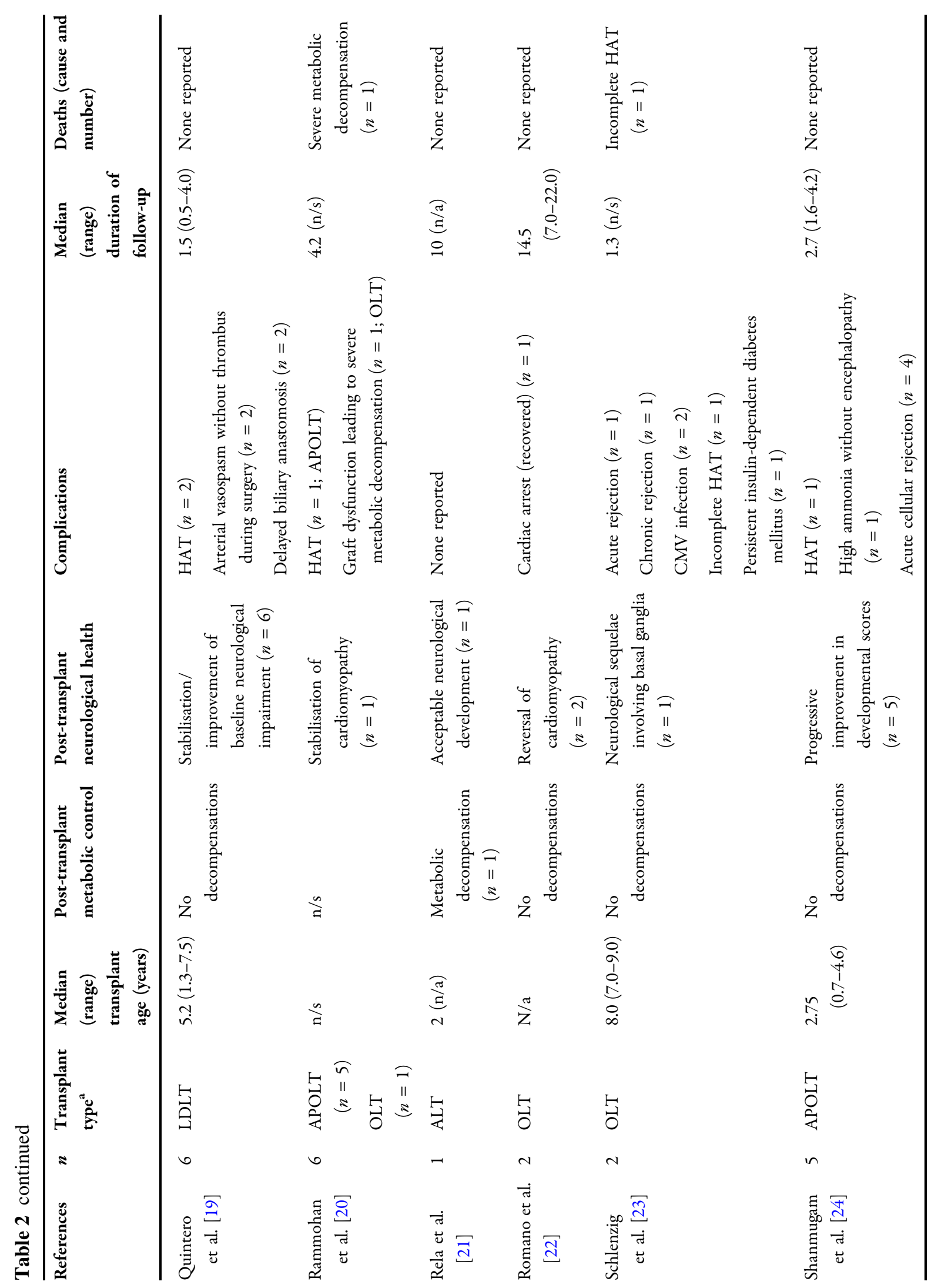




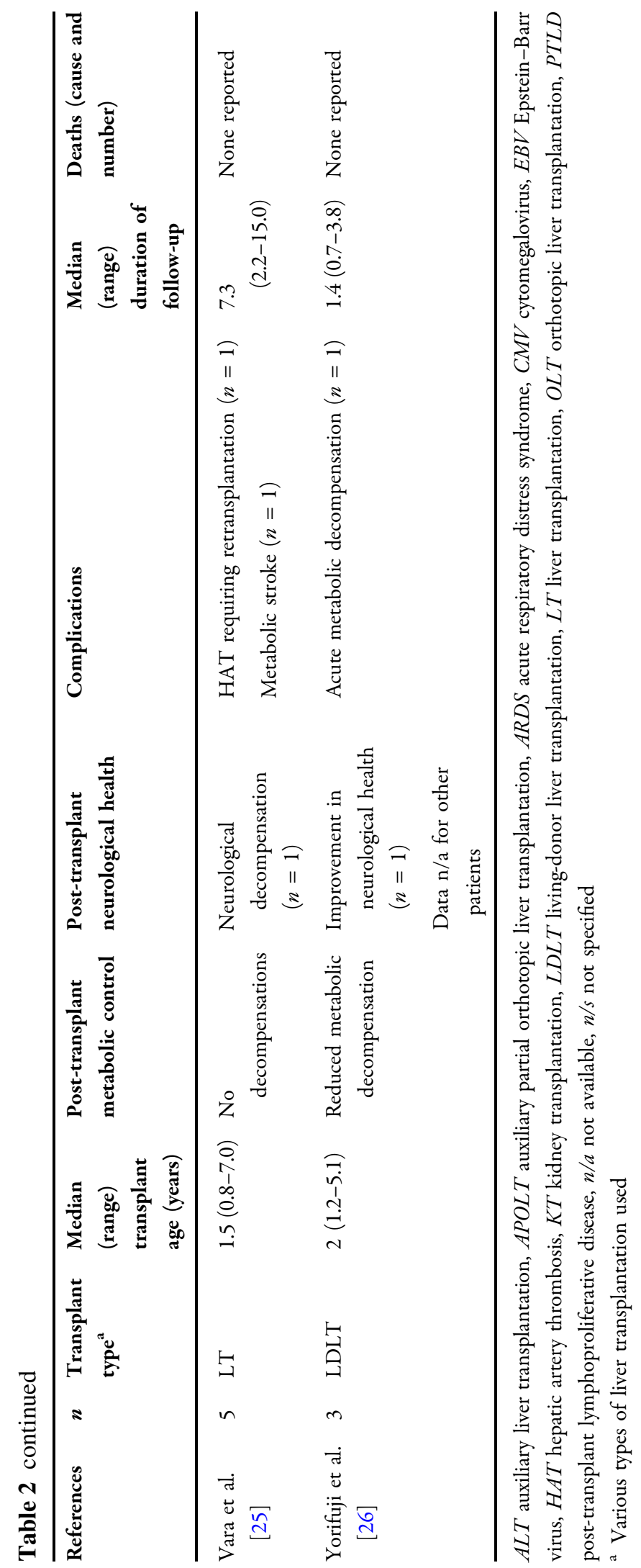




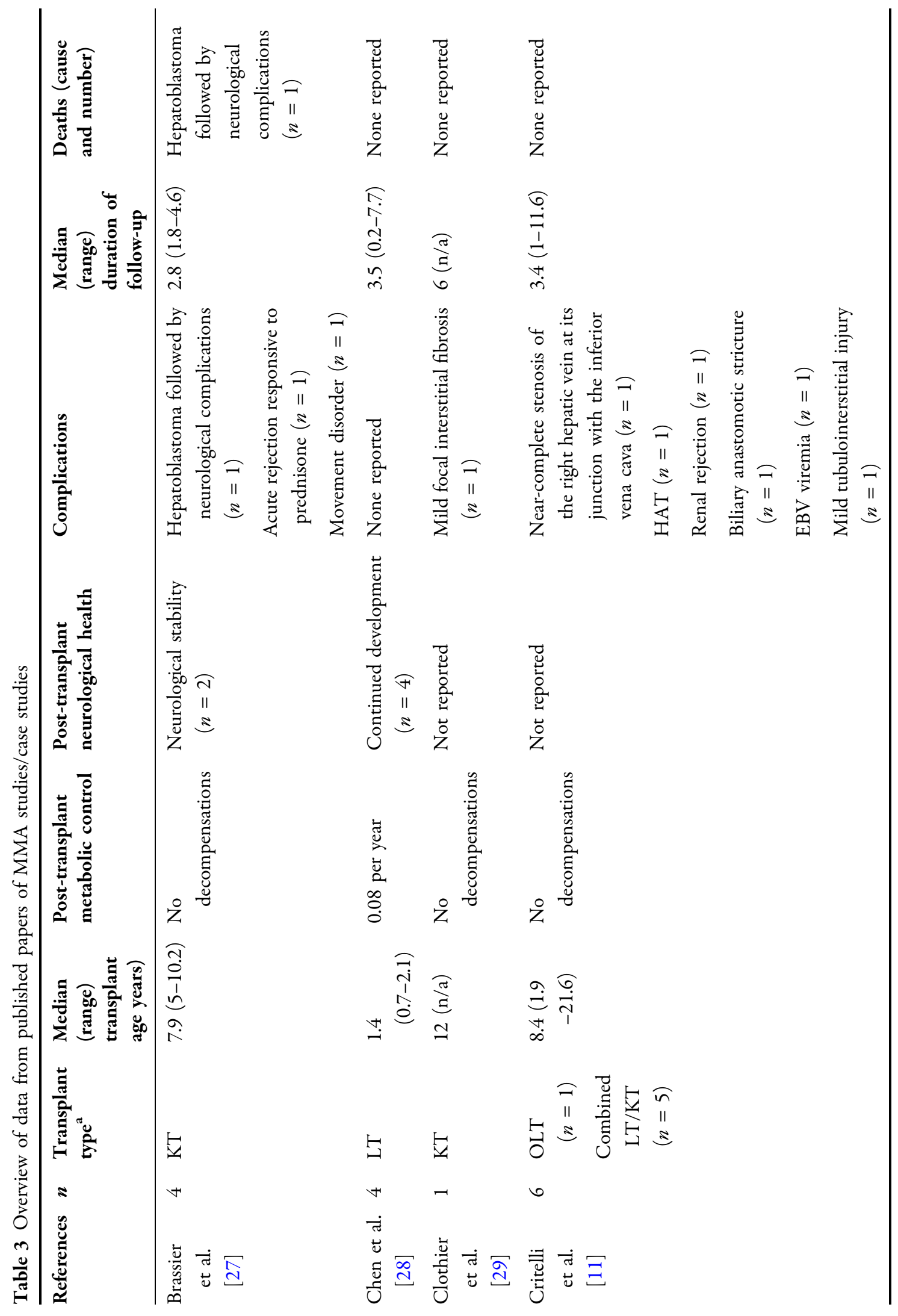




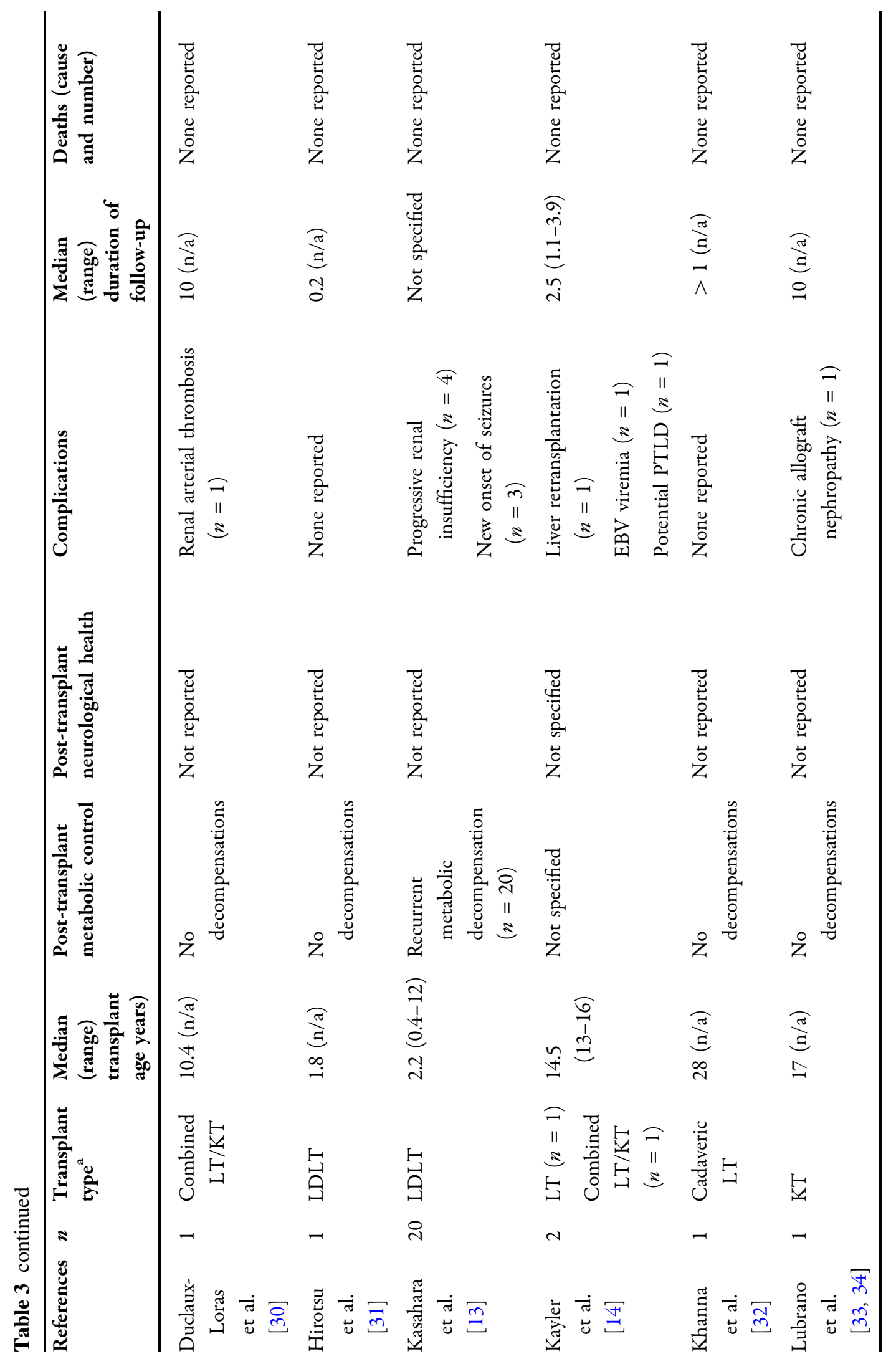




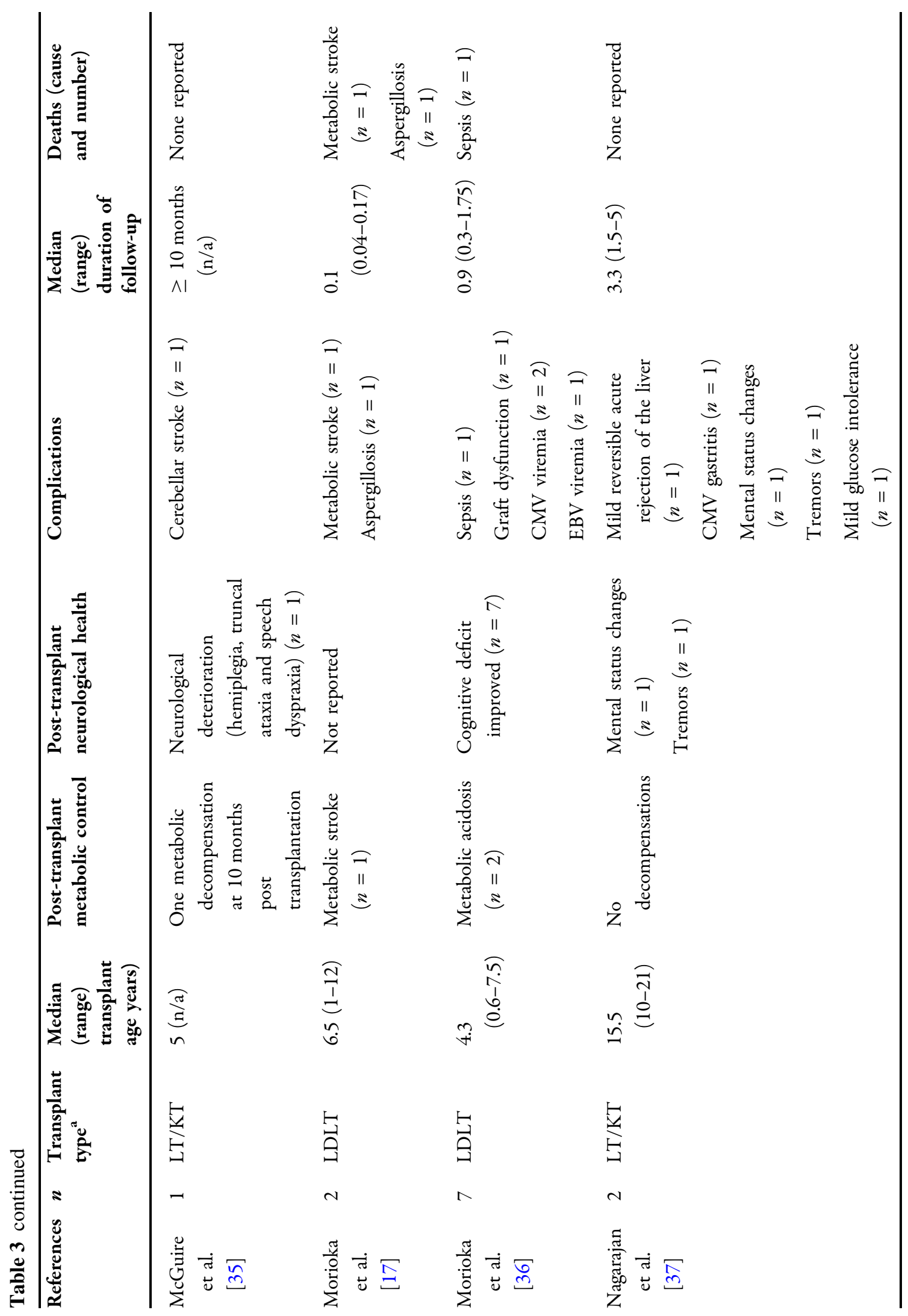




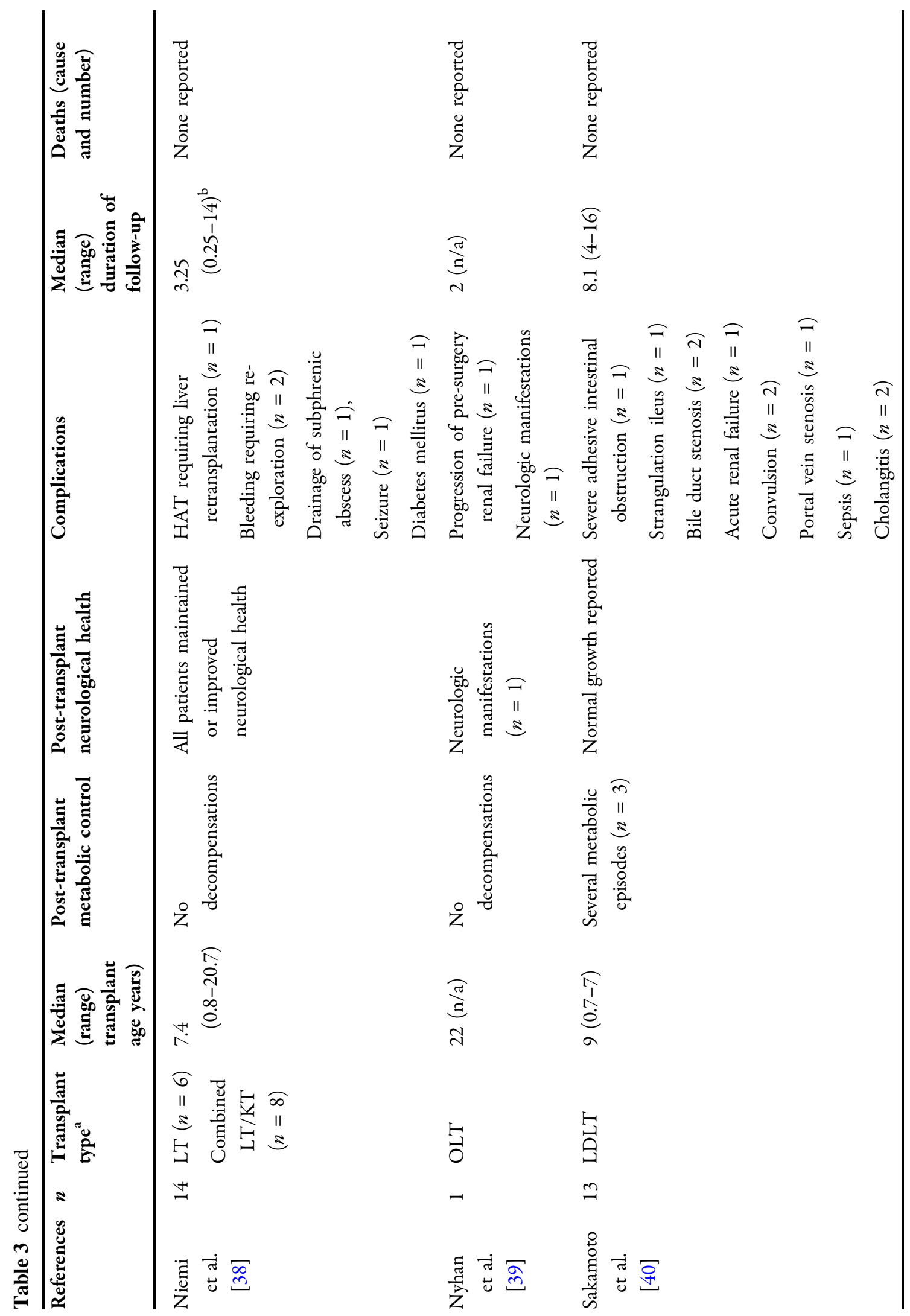




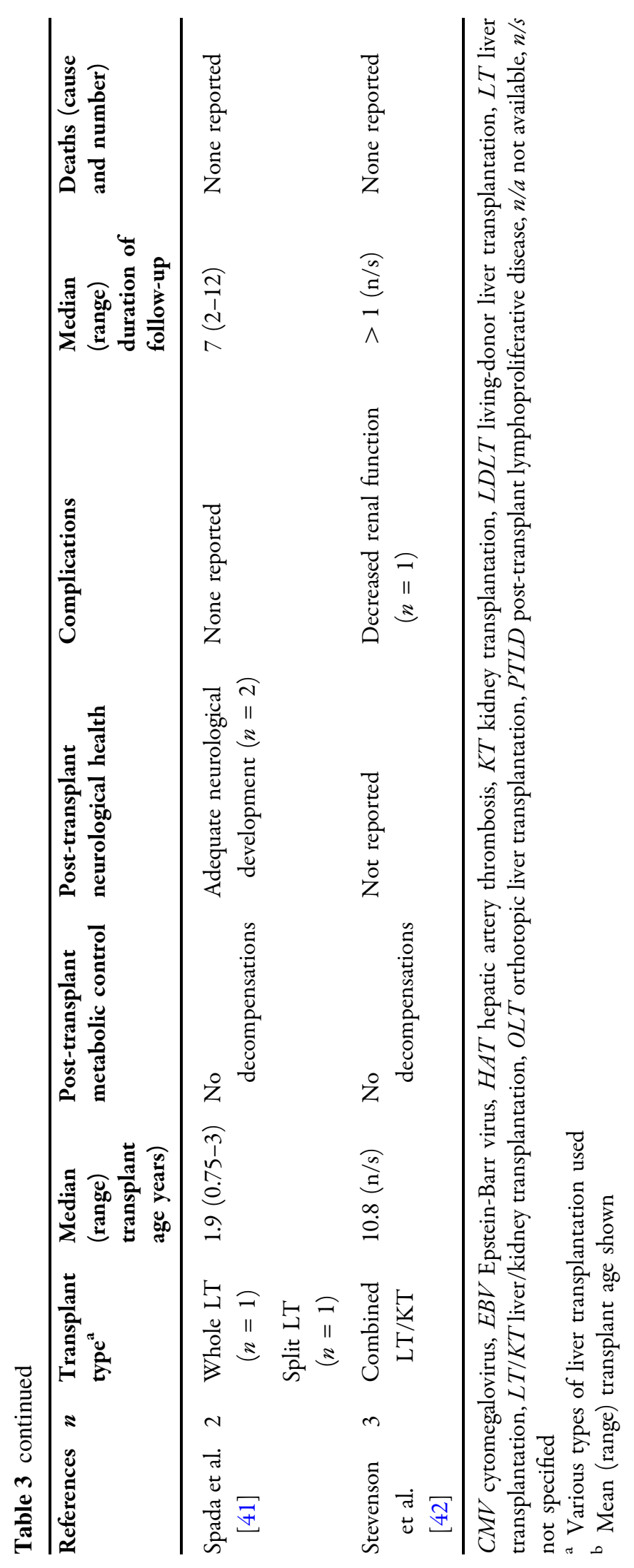




\section{Mortality}

A total of 27 post-transplant deaths were reported in patients with $\mathrm{PA}$, which equated to a mortality rate of $14.0 \%(27 / 194)$. For patients with MMA, 18 post-transplant deaths were reported, which equated to a mortality rate of $11 \%(18 / 167)$. Causes of death for PA and MMA are presented in Tables 2 and 3, respectively.

\section{$P A$}

A retrospective analysis of 12 patients with PA who underwent liver transplantation reported that while the graft survival rate was $60 \%$ at 5 years, seven of the 12 patients (58\%) died within the first year after transplantation (multi-organ failure, $n=4$; hepatic failure, $n=3$ ) [10]. Infection is reported as a major cause of post-transplant deaths in patients with PA: Kasahara et al. [13] reported that liver transplantation in nine patients with PA resulted in four sepsis-related deaths, equating to a mortality rate of $44 \%$. However, some studies suggest that transplantation appears to be less of a risk in some patients with PA. For example, a recent retrospective analysis of liver transplantation by Shanmugam et al. [24] reported survival in patients with PA to be $100 \%$ at a median follow-up of 32 months. It appears that survival following transplantation in patients with PA seems to be improving with greater experience of the procedure. Indeed, the expertise and experience of the surgical team is an important prognostic factor for general paediatric liver transplantation [43-46].

\section{MMA}

Patient mortality following transplantation was less frequently reported in patients with MMA compared with patients with PA, with most studies reporting $100 \%$ patient survival. However, three studies identified a post-transplantation mortality risk in patients with MMA. For kidney transplantation, Brassier et al. [27] reported four patients with MMA [median transplantation age 7.9 years (range 510.2 years)] who received a kidney graft fol- lowing repeated metabolic decompensations, with progression to chronic kidney disease (CKD) in three of these patients (end-stage kidney disease in two patients and CKD stage III in one patient; normal renal function in one patient) prior to transplantation. One patient developed a hepatoblastoma at the age of 11 (less than 2 years post-surgery), followed by neurological complications and death. The three other patients remained alive, with two achieving neurological stability. Morioka et al. [17] reported on two patients with MMA who both died after receiving a liver transplantation, equating to a $100 \%$ mortality rate; these deaths were caused by metabolic stroke and aspergillosis. One death caused by a metabolic crisis was identified in a patient with MMA following combined liver-kidney transplantation [47].

\section{Complications}

A total of 62 complications (various types) were reported in 115 patients with PA. This equates to an approximate complication rate of $54 \%$ given that some patients experienced more than one complication. Cardiomyopathy $(n=12)$, hepatic arterial thrombosis (HAT; $n=14)$ and viral infections $(n=12)$ were most commonly reported complications among patients with PA. A total of 52 complications were reported in 106 patients with MMA. This equates to an approximate complication rate of $49 \%$ given that some patients experienced more than one complication. Viral infections $(n=14)$ and renal failure/impairment $(n=10)$ were most commonly reported complications among patients with MMA. Of note, the definition of what constituted a 'complication' varied widely between publications. Post-transplant complications for patients with PA and MMA are presented in Tables 2 and 3, respectively.

\section{$P A$}

Complications related to the transplant procedure along with subsequent post-surgery infection appeared to be most commonly reported in 
patients with PA (Table 2). A retrospective study reported that out of 17 liver transplantation procedures in 12 patients with PA, HAT was reported in a total of six transplants (equating to a $35 \%$ risk of HAT), and occurred in successive grafts in two patients [10]. Similarly, Critelli et al. [11] reported that two of three patients with PA who received a liver transplant developed a recurrent left HAT (equating to a $66 \%$ chance of HAT), one that required Fogarty catheter thrombectomy and one that did not resolve despite placement of an aortic conduit graft, resulting in an associated hepatic allograft infarction. The same study noted that one patient developed cytomegalovirus (CMV) viremia, while a similar retrospective review of children with PA noted that two of three patients developed CMV infection following liver transplantation [12]; all episodes of CMV infection were successfully treated with intravenously administered ganciclovir.

\section{MMA}

Post-transplantation complications varied amongst patients with MMA, although most studies reported at least one complication (Table 3). Complications following combined liver/kidney transplantation included renal artery thrombosis (Duclaux-Loras et al. [30]) and cerebellar stroke [35]. For liver transplantation, complications such as infection (sepsis, CMV and Epstein-Barr virus [EBV]) [36] and HAT $[11,38]$ were reported. Complications following kidney transplantation included hepatoblastoma [27] and chronic allograft nephropathy [33].

\section{Post-transplant Metabolic Episodes}

\section{$P A$}

In the literature available for patients with PA, reports of metabolic episodes ranged from $0 \%$ to $100 \%$ following liver transplantation (Table 2). A retrospective analysis of 12 patients with PA reported no further episodes of acute metabolic decompensation following liver transplantation even with a less restricted dietary protein intake
[10]. Similarly, Shanmugam et al. [24] reported that of five children with PA and a median of eight episodes of decompensation per year prior to transplantation, no episodes of metabolic decompensation occurred either intraoperatively or immediately after transplantation when receiving a protein-unrestricted diet. In contrast, Kasahara et al. [13] reported that following liver transplantation in Japanese patients with PA/MMA, recurrent metabolic decompensation was observed in $100 \%$ of patients despite the administration of protein restriction with medications (cobalamin, carnitine supplementation, and antibiotics to eradicate gut flora). Thus, post-transplant medication for the original liver disease had to be continued in all patients.

\section{$M M A$}

In the literature available for patients with MMA, episodes of metabolic decompensation varied by transplantation type (Table 3). For patients with MMA, the risk of further episodes of metabolic decompensation appeared to be higher following liver transplantation compared with kidney or combined kidney/liver transplantation. Kasahara et al. [13] reported recurrent metabolic decompensation in 100\% of patients with MMA following liver transplantation despite the administration of protein restriction with medications, leading to the continuation of pre-surgery medication. Sakamoto et al. [40] reported that while the number of acidosis attacks significantly decreased following liver transplantation in Japanese patients with MMA, this was not deemed to be a 'curative' approach as most patients remained on a protein-restricted diet. Morioka et al. reported episodes of metabolic stroke [17] and metabolic episodes [36] following liver transplantation. In contrast, Niemi et al. [38] reported no further episodes of metabolic decompensation following liver transplantation in patients with MMA. patients with MMA who received kidney transplantation or combined liver/kidney transplantation typically reported no further metabolic decompensations. McGuire et al. [35] reported the case study of a 
patient who received a combined liver/kidney transplant at 5 years, with subsequent metabolic decompensation at 10 months post-surgery; however, no further episodes of metabolic decompensation were reported.

\section{Can Transplantation Reverse Cardiomyopathy in Patients with PA?}

Overall, liver transplantation was shown to effectively reverse baseline cardiomyopathy in approximately $50 \%$ of patients at post-transplant follow-up. Romano et al. [22] reported that of patients with PA who survived their first year of life, a dilated cardiomyopathy developed in six patients at a median age of 7 years (range 5-11 years), although this was reversed in two patients within 1 year following liver transplantation. Charbit-Henrion et al. [10] similarly reported reversal of cardiomyopathy in three patients with PA following liver transplantation, although three patients with normal heart ultrasound prior to transplantation subsequently developed unexpected heart failure and died at 1-4 weeks following surgery. Of note, transplantation is typically contraindicated in patients with severe heart disease.

\section{DISCUSSION}

This review has shown that liver, kidney, or combined liver-kidney transplantation can significantly improve metabolic outcomes for patients with PA or MMA. However, data from retrospective and case studies suggest that this approach cannot be considered to be a cure, and all three types of transplantation are associated with significant risks of subsequent complications or death.

A number of factors influence the choice of therapy (liver or kidney transplant alone or combined liver-kidney transplantation) in patients with PA or MMA. In general, liver transplantation is deemed to be a suitable treatment option for patients with PA and those patients with MMA but without renal impairment. In contrast, combined liver-kidney transplantation is considered more suitable in those patients with MMA and renal impairment. In addition, it is important to recognise the indications and contraindications for the use of transplantation in PA/MMA. Traditionally, transplants have been reserved for the most 'brittle' patient, in whom it is difficult to achieve reasonable metabolic control or that their dietary restriction is very severe and still not achieving metabolic control. More recently, there has been a tendency to transplant at an earlier stage, regardless of the level of metabolic control. One reason behind this approach is the increased availability of transplant units. However, to support the optimal outcome of patients with PA/MMA, it is important that these transplant units have relevant and suitable experience in transplanting patients with metabolic disorders rather than patients with organ failure alone.

The use of transplantation in patients with PA/MMA typically occurs at a young age, although transplantation at adult age has been reported when other management approaches have proven to be unsuccessful. Frequent metabolic decompensations tend to be the most common indication for transplantation in PA/ MMA, although other reasons include suboptimal metabolic outcomes despite medical therapy, elective transplantation in view of the natural history of the disease, and the prevention of ongoing long-term complications of the disease. Current Scottish Intercollegiate Guidelines Network (SIGN) guidelines for the management of PA and MMA recommend that liver and/or kidney transplantation should be considered in patients with frequent metabolic decompensations where the clinical condition is difficult to stabilise with dietary/pharmacological treatment [1]. A catabolic state or active metabolic decompensation would be a potential contraindication to transplantation; thus clinicians need to carefully consider related risks and benefits prior to surgery.

The success of transplantation in PA/MMA remains varied, with substantial rates of associated complications and deaths being reported. While the risk of episodes of metabolic decom- 
pensation are reduced, a proportion of transplanted patients continue to have episodes (approx. 15\%). Martinelli et al. [48] note that while transplanted organs (liver and/or kidney) are an enzyme source, they only partially correct the biochemical defect. However, the small amount of enzyme activity gained by kidney transplantation appears sufficient to improve the metabolic balance in patients with MMA [1]. This could explain why metabolic acidosis was more commonly reported after liver transplantation compared with kidney or combined liver-kidney transplantation. In addition, the risk of subsequent episodes of metabolic acidosis following transplantation may be higher in those patients offered a less restricted dietary protein intake, in contrast with those who remain on a protein-restricted diet and/or receive appropriate pharmacotherapy to support metabolic stabilisation.

As transplantation is not curative in PA/ MMA, it is important to recognise that any improvement in metabolic control has to be balanced with the possibility of complications during surgery and following transplant, along with the need for prolonged immunosuppressive therapy. A number of factors may influence the occurrence of post-operative mortality and/ or complications. For example, high-level expertise of the transplant team and transplant centre has the potential to reduce post-operative mortality and an experienced team would also recognise that patients with PA/MMA undergoing transplantation would need careful and prolonged management following surgery. As such, the transplant team should aim to work closely with the metabolic team to support the optimal peri- and post-operative management of the patient's primary metabolic disorder, be it PA or MMA. The use of immunosuppressive therapy, along with the management of any associated tolerability issues, also remains important following transplantation. Extra-hepatic risks remain following surgery in patients with PA and MMA, with transplantation simply aiming to provide a milder and more manageable phenotype of the disease. Patients will therefore be required to remain on a protein-restricted diet, albeit a less stringent one. Of note, patients with PA or MMA should avoid prolonged fasting and dextrose infusions following transplantation in order to promote anabolism and prevent metabolic decompensation perioperatively. In addition, regular renal surveillance is also advised post-transplant in the long term.

Preoperative conditions associated with PA and MMA, such as intellectual disability, preexisting neurological impairment, and cardiomyopathy, may influence the lifespan of a patient following transplantation. However, the optimal management of metabolic status both perioperatively and following transplantation would serve to minimise any further deterioration of these preoperative conditions. In addition, existing cardiac complications in patients with PA have the potential to improve following liver transplantation. It should be noted that liver and/or kidney transplantation does not reverse any neurologic injury that has accumulated prior to surgery. Of note, SIGN guidelines suggest that transplantation should ideally occur prior to any severe neurological deterioration and under stable metabolic conditions [1]. Thus, residual neurologic injury remains a persistent disease complication suggesting that postponing a transplant to a later stage may lead to additional neurologic insults and possibly inferior neurodevelopmental outcomes. However, post-transplant neurological deterioration in organic acidurias has also been reported (e.g. [39, 49]. De novo MMA production in the central nervous system may contribute to neurological dysfunction given that organ transplantation does not affect the concentration of MMA in the cerebrospinal fluid [48].

Worsening renal function was reported in some patients with PA following liver transplantation, although combined liver-kidney transplantation appeared more likely to result in stable renal function. In addition, significant recovery of cardiac function/reversal of severe cardiomyopathy was reported in some patients 
with PA following transplantation, although heart failure was reported as the cause of death in other patients. Thus, cardiac and renal function should be assessed before transplantation and monitored closely afterward, with consideration given to the use of renal-sparing immunosuppression following surgery.

This review identified that the transplantation process itself was associated with several surgical complications, with liver transplantation associated with a higher level of mortality compared with kidney and combined liver-kidney transplantation. HAT remains a serious life-threatening complication in liver transplantation as noted in our findings. The overall incidence of HAT following liver transplantation varies from $2 \%$ to $9 \%$ and represents one of the main causes of graft loss and transplant recipient mortality [50]. The mechanism of HAT development is not fully understood, although young donor age and small liver graft are reported as risk factors in paediatric deceased-liver transplantation [51]. Infection, particularly CMV and EBV viremia, was also commonly reported, particularly in liver transplantation patients. Infection was a predominant cause of post-transplantation death, particularly in patients with MMA, and graft rejection/dysfunction leading to death was also reported. The most common reason reported for retransplantation in both patients with PA and MMA was HAT. Other complications which limited post-transplantation survival included cardiac failure and metabolic stroke. Of note, children with organic acidemias appear to be at higher risk of complications from transplantation than other metabolic disorders [52].

When considering the type of liver transplantation, SIGN guidelines recommended OLT, as this appears to be associated with fewer complications compared with auxiliary liver transplantation $[1,36]$. However, any benefits of transplantation must always be weighed against the risks associated with organ transplantation along with the need for long-term immunosuppression $[1,36]$. Toxicity associated with the use of post-transplantation immunosuppressive agents does occur, e.g. cyclosporine $\mathrm{A}$ and tacrolimus-induced leukoencephalopathy is a significant complication which may occur at therapeutic levels [53].

The findings from the current narrative review are in line with preliminary findings from a recent systematic review of the use of transplantation in patients with PA and MMA. This also demonstrated that while liver and/or kidney transplantation can improve patient outcome, the potential for increased mortality risk and a high risk of complications also need to be considered [54].

This review has a number of limitations. The search strategy used for this review identified 70 suitable references comprising both abstracts and full papers, although the available level of patient information, assessed clinical parameters, and clinical outcomes varied between them. All references were crosschecked to avoid any possible duplication of data between abstracts and full papers, although this was limited by the lack of patient information and clinical data provided in some of the abstracts meaning that the total number of transplants performed was actually lower than that reported. A number of these references were pooled studies of metabolic disease wherein only a few patients had PA or MMA. In addition, duration of follow-up varied substantially between studies, with some studies not providing timings of follow-up or complications, and some clinical outcomes of baseline parameters were not reported. For deaths related to transplantation, some references, particularly abstracts, failed to provide full details of the cause of these deaths, which was typically compounded by a lack of specific patient information. Likewise, for complications of transplantation surgery, some studies specifically defined and assessed complications, while others failed to do so, or failed to provide specific patient details, leaving the reader to subjectively interpret any issues related to the transplantation procedure. For this reason, the overall data included in this review should simply be used as a guide to the current issues related to transplantation in patients with PA and MMA. 


\section{CONCLUSIONS}

In summary, while the use of liver transplantation and combined liver-kidney transplantation appears to benefit some patients with PA or MMA, respectively, this approach does not provide a metabolic cure and patients remain at risk from disease-related and transplantationrelated complications. Any transplantation procedure also has an associated mortality risk. Thus, all treatment avenues should ideally be exhausted for PA/MMA before selecting transplantation. If liver and/or kidney transplantation remains a viable option, the benefits of this approach must be individually and meticulously weighed against the risk of perioperative complications, including renal and neurological progressive impairment in the post-transplant period.

\section{ACKNOWLEDGEMENTS}

Funding. Rapid Service and Open Access fees for this publication were funded by Recordati Rare Diseases, Puteaux, France.

Medical Writing and Editorial Assistance. Editorial assistance in the preparation of this article was provided by Matthew Joynson of Springer Healthcare Ltd. Support for this assistance was funded by Recordati Rare Diseases, Puteaux, France.

Authorship. All named authors meet the International Committee of Medical Journal Editors (ICMJE) criteria for authorship for this article, take responsibility for the integrity of the work as a whole, and have given their approval for this version to be published.
Disclosures. Sufin Yap has received funding for travel to conferences, honoraria from Recordati Rare Diseases. Roshni Vara has received honoraria from Recordati Rare Diseases. Ana Morais has received honoraria from Recordati Rare Diseases.

Compliance with Ethics Guidelines. This article is based on previously conducted studies and does not contain any studies with human participants or animals performed by any of the authors.

Data Availability. All data generated or analysed during this study are included in this published article/as supplementary information files.

Open Access. This article is licensed under a Creative Commons Attribution-NonCommercial 4.0 International License, which permits any non-commercial use, sharing, adaptation, distribution and reproduction in any medium or format, as long as you give appropriate credit to the original author(s) and the source, provide a link to the Creative Commons licence, and indicate if changes were made. The images or other third party material in this article are included in the article's Creative Commons licence, unless indicated otherwise in a credit line to the material. If material is not included in the article's Creative Commons licence and your intended use is not permitted by statutory regulation or exceeds the permitted use, you will need to obtain permission directly from the copyright holder. To view a copy of this licence, visit http:// creativecommons.org/licenses/by-nc/4.0/.

\section{APPENDIX}

See Tables 4 and 5. 


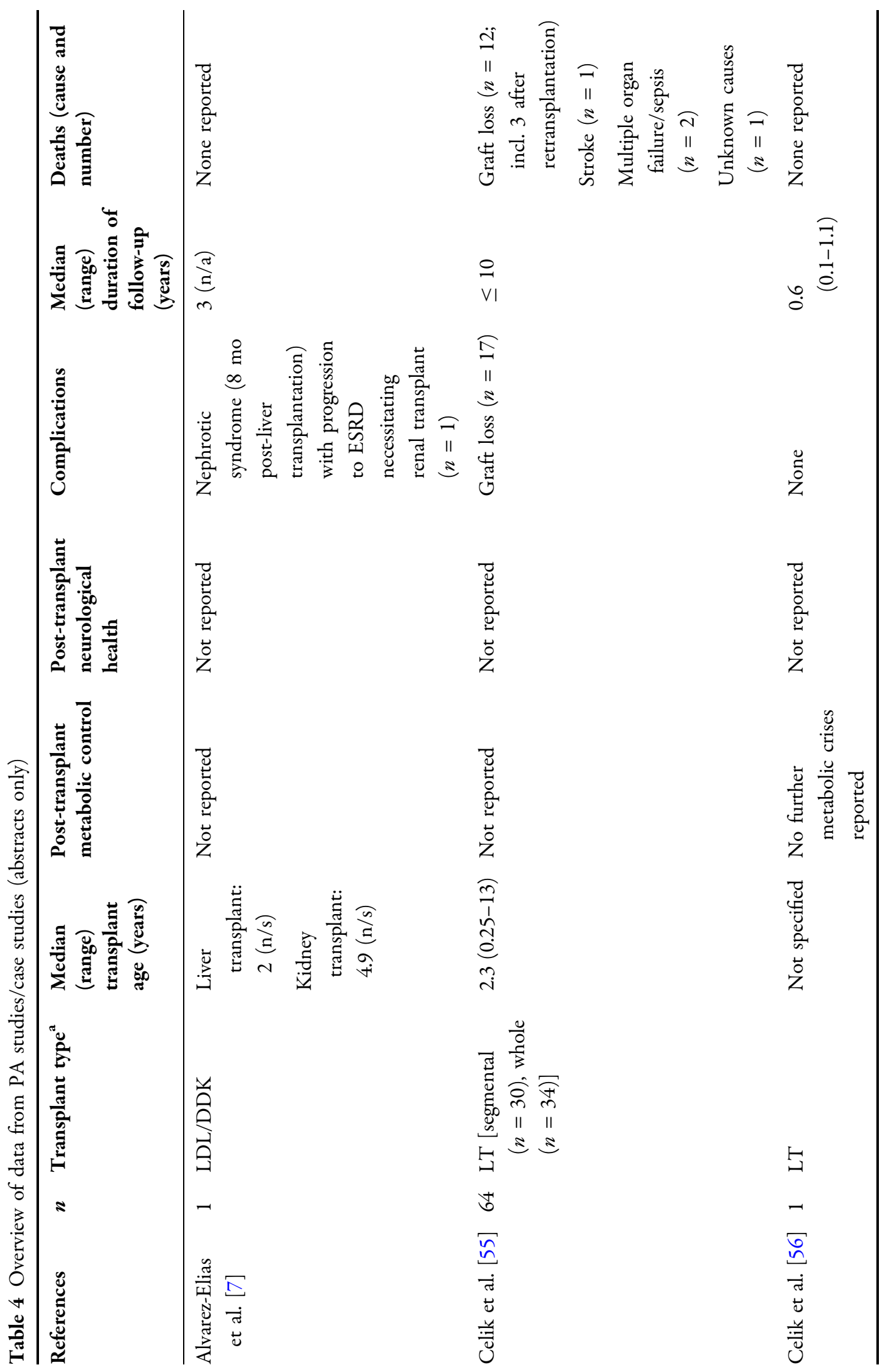




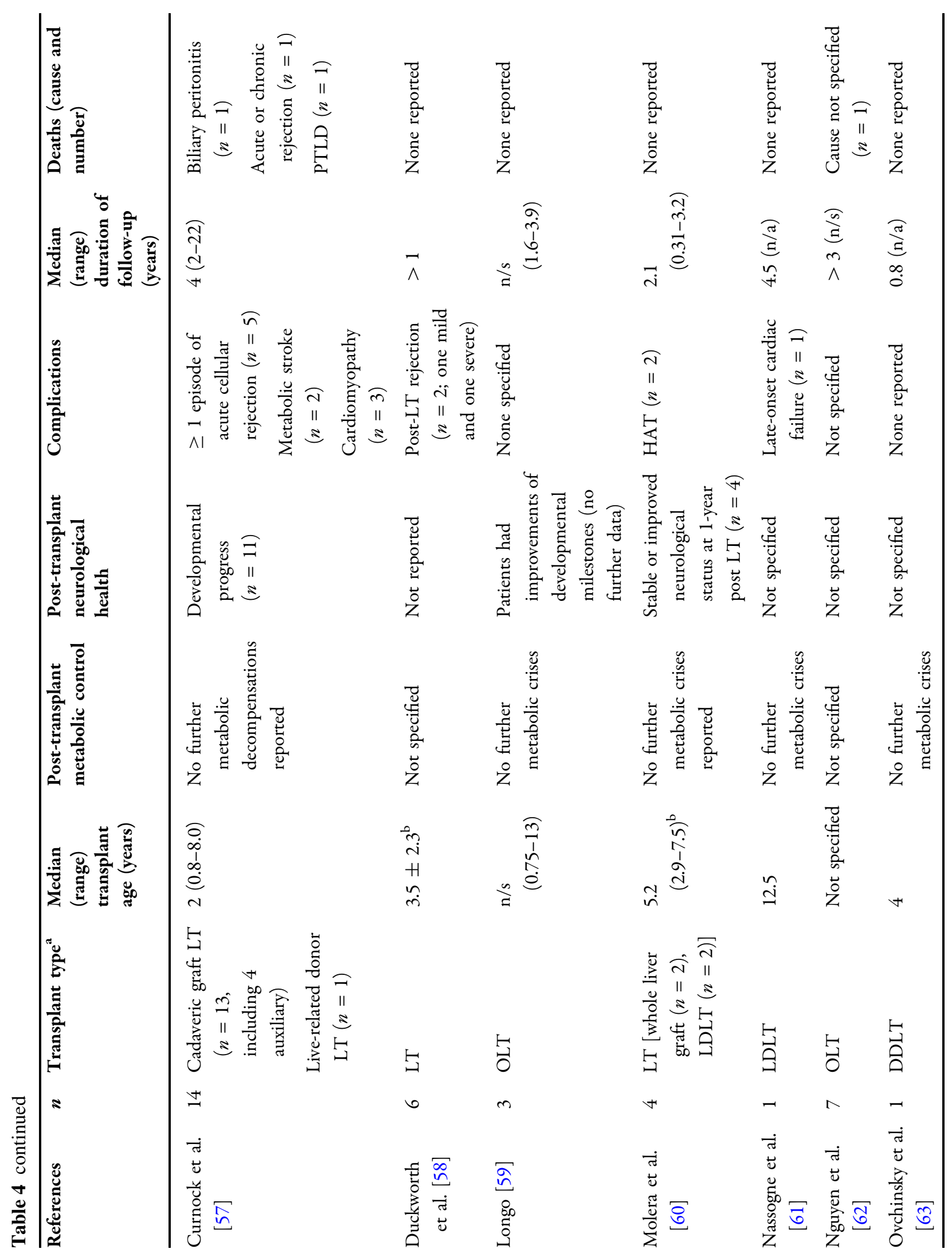




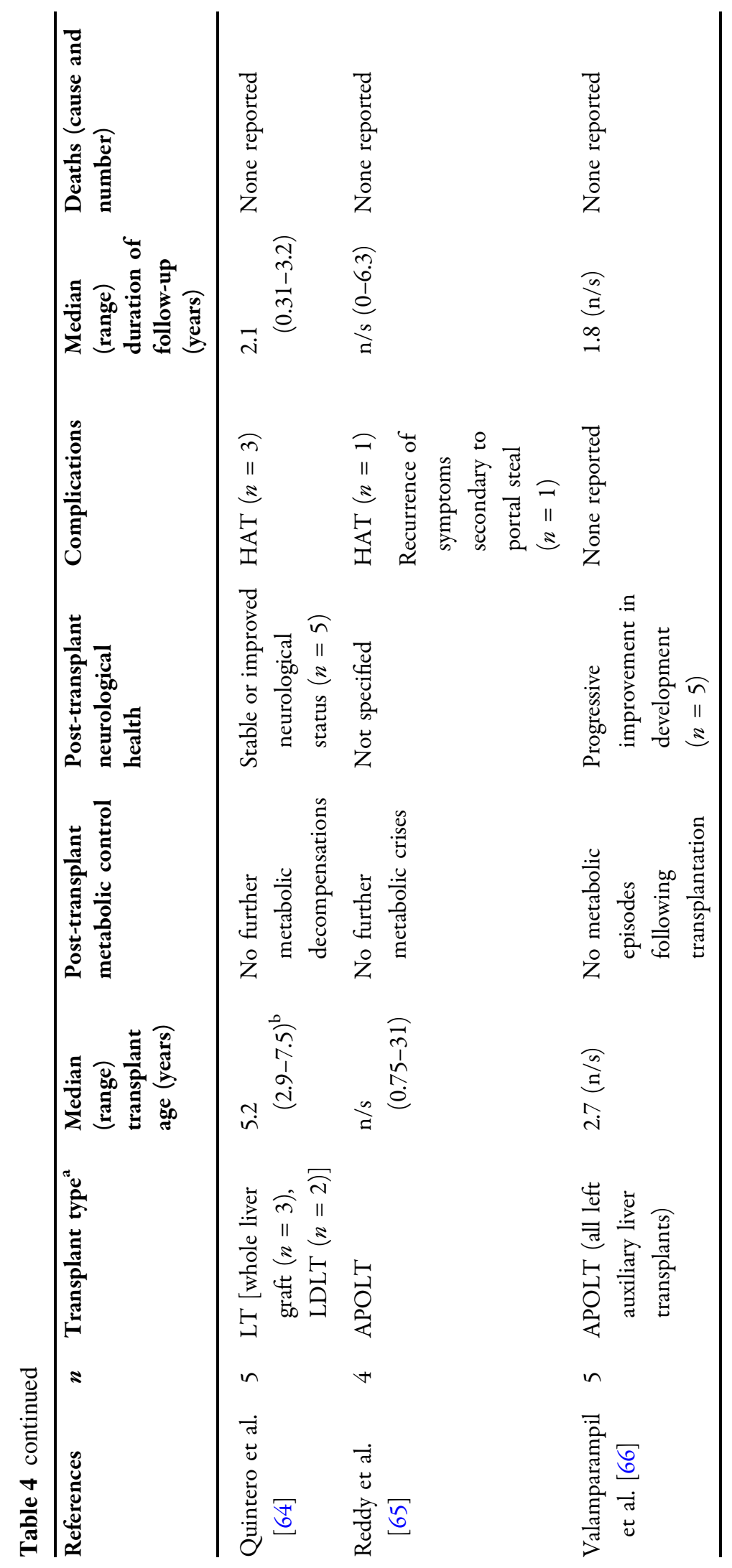




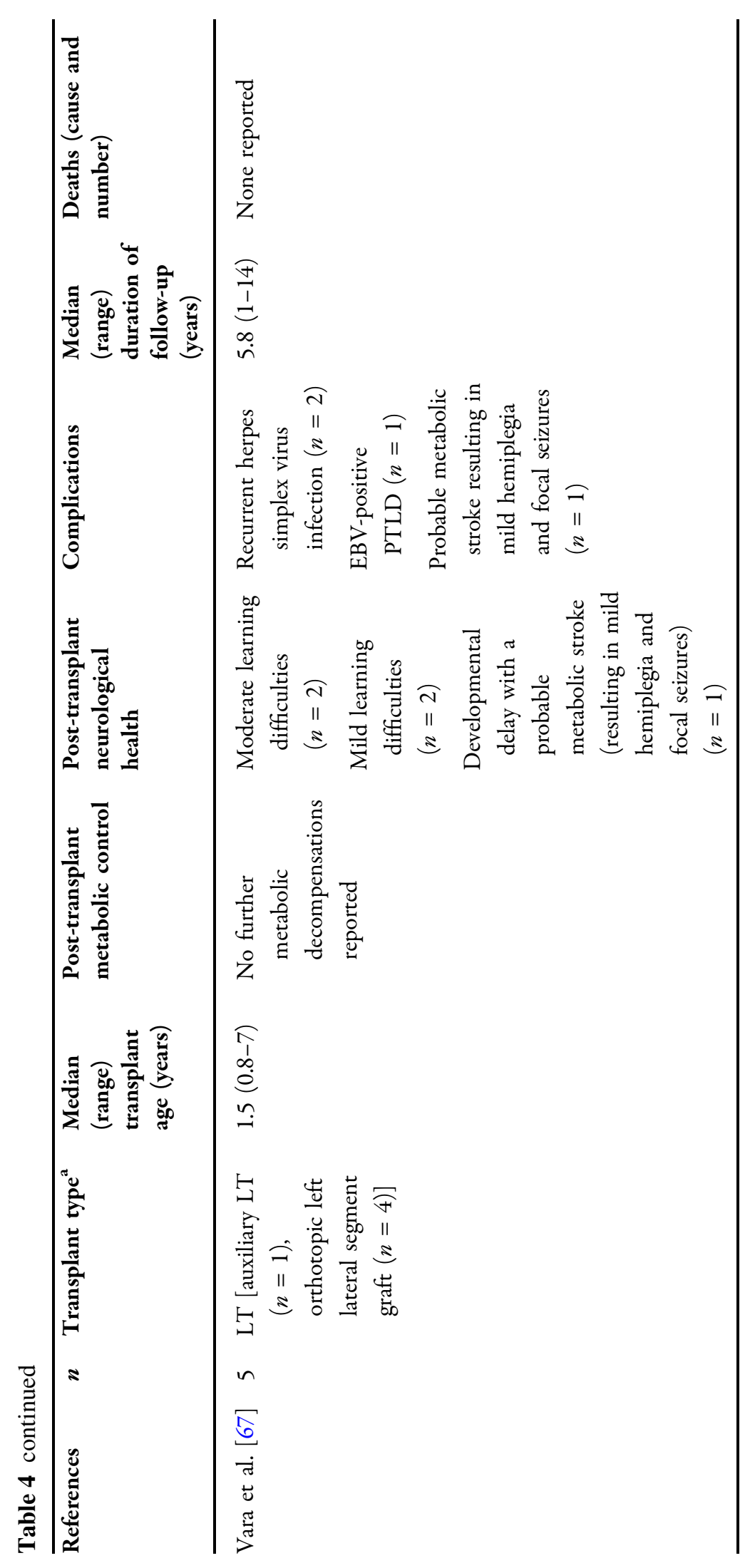




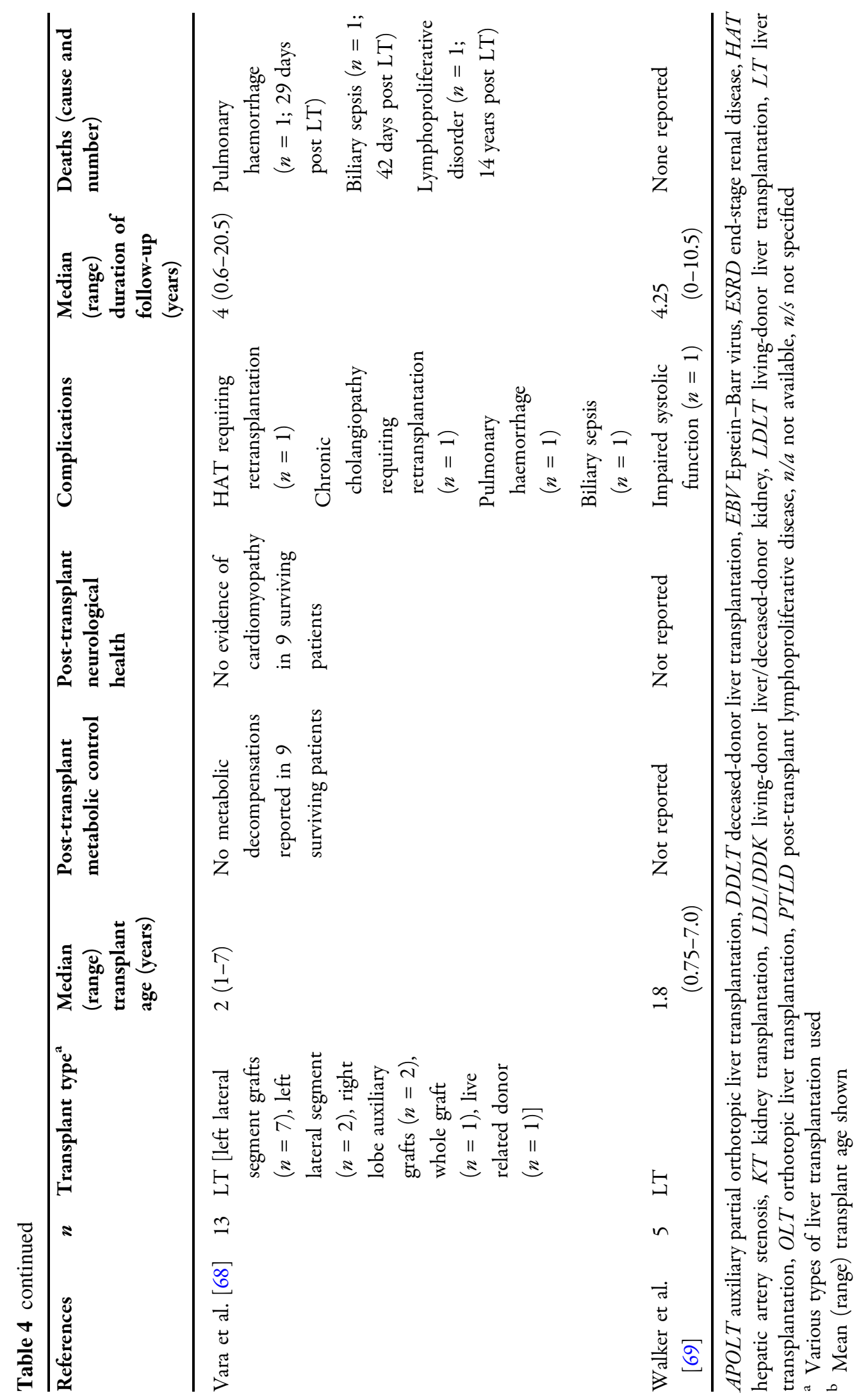




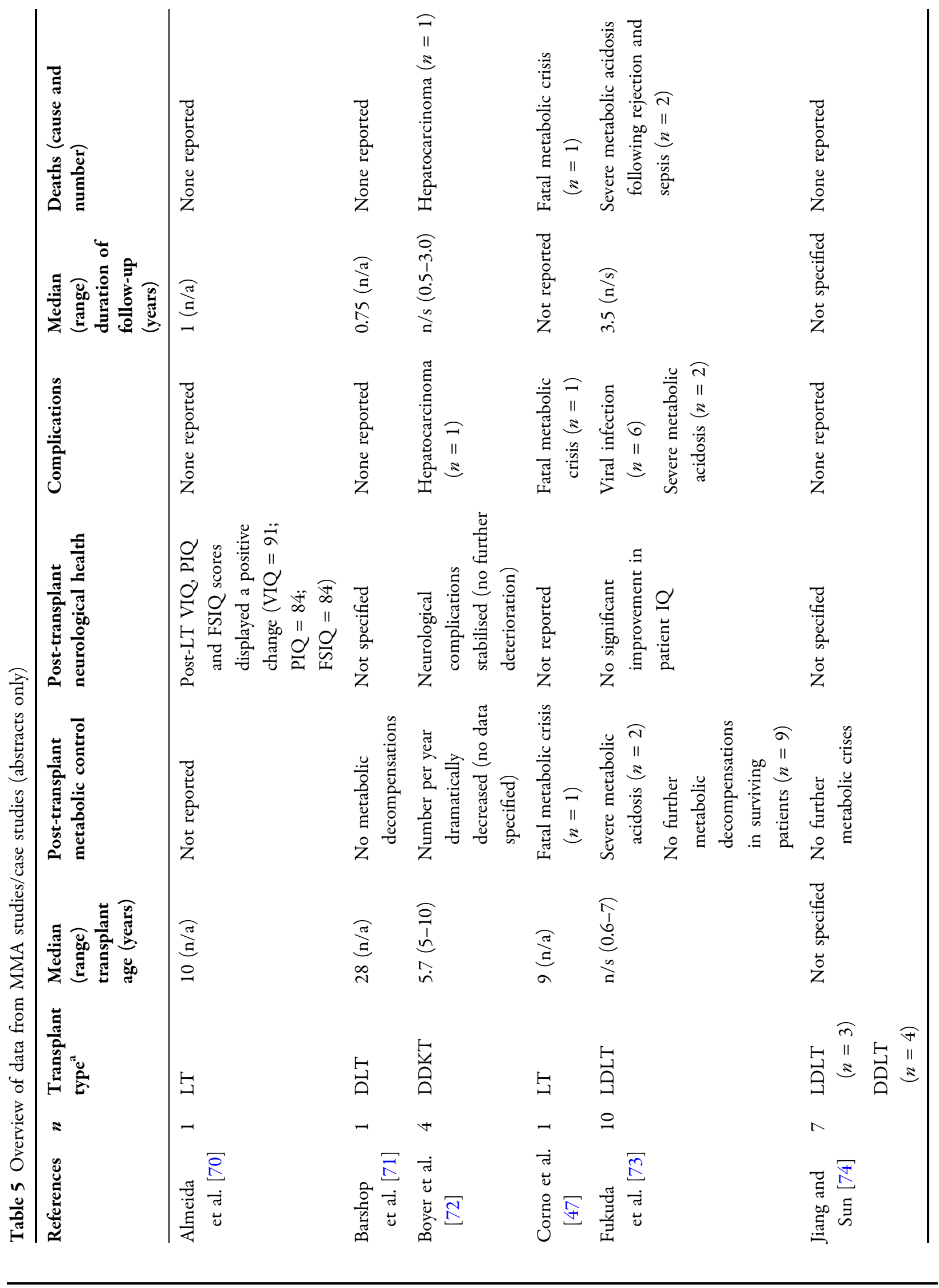




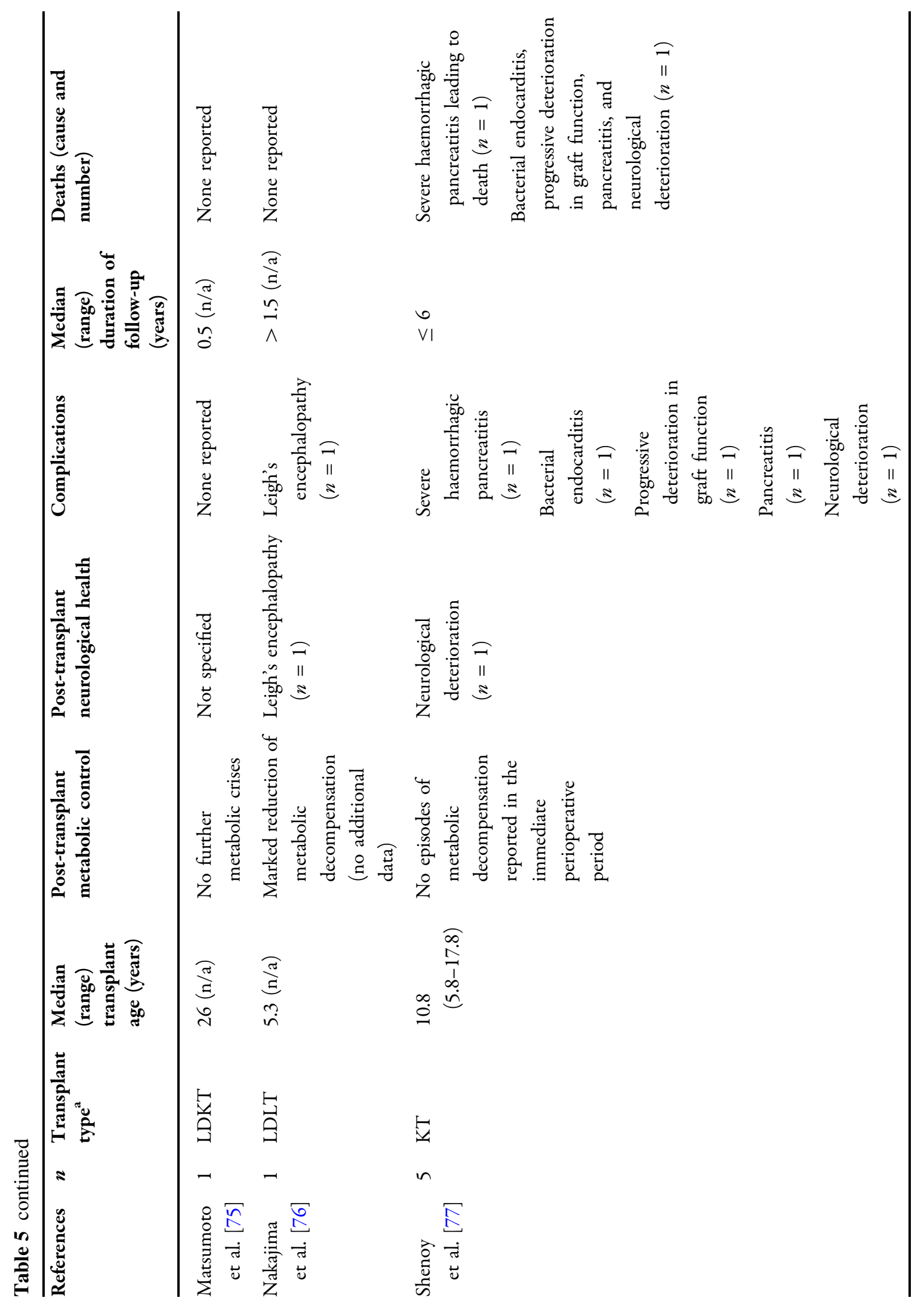




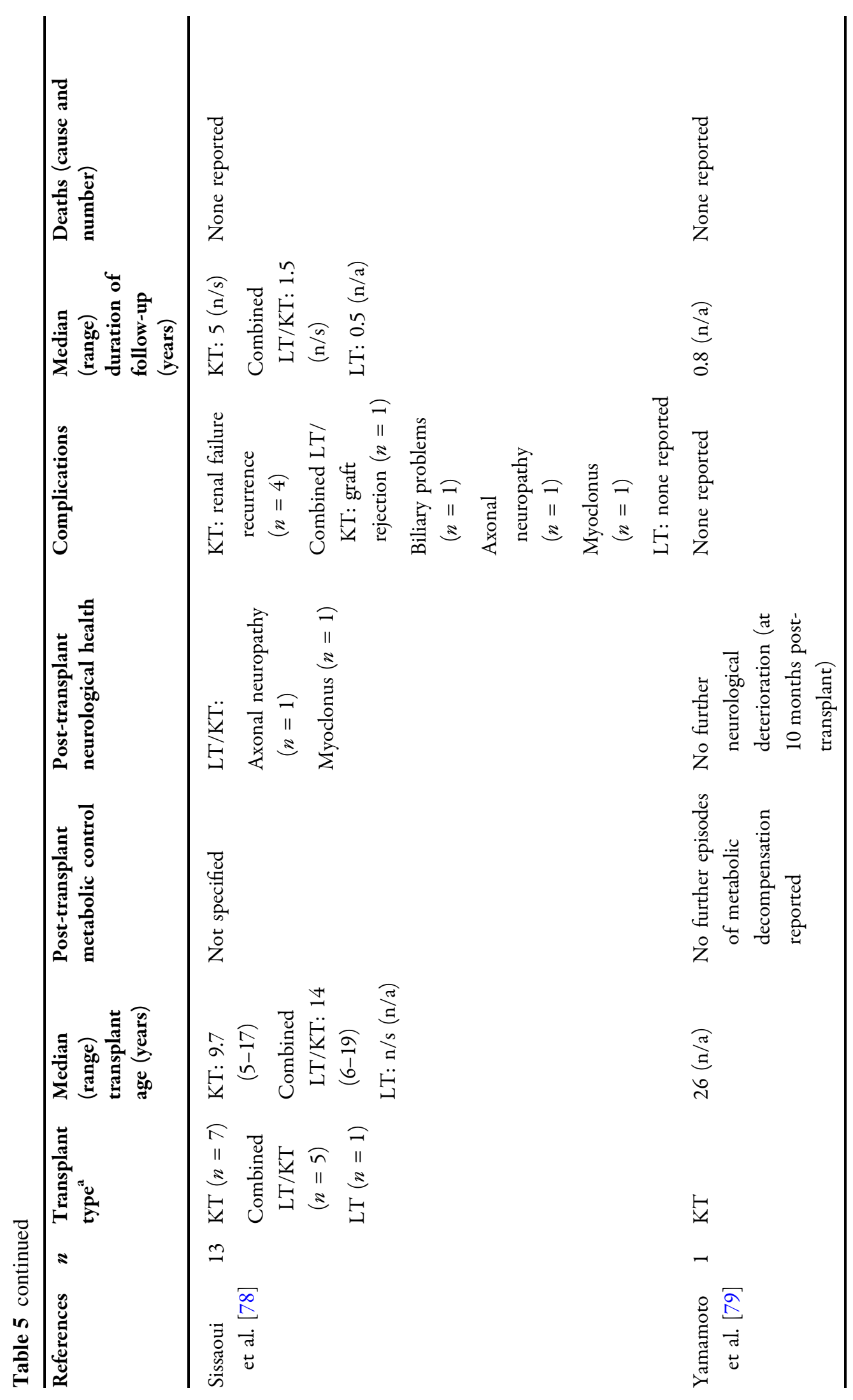




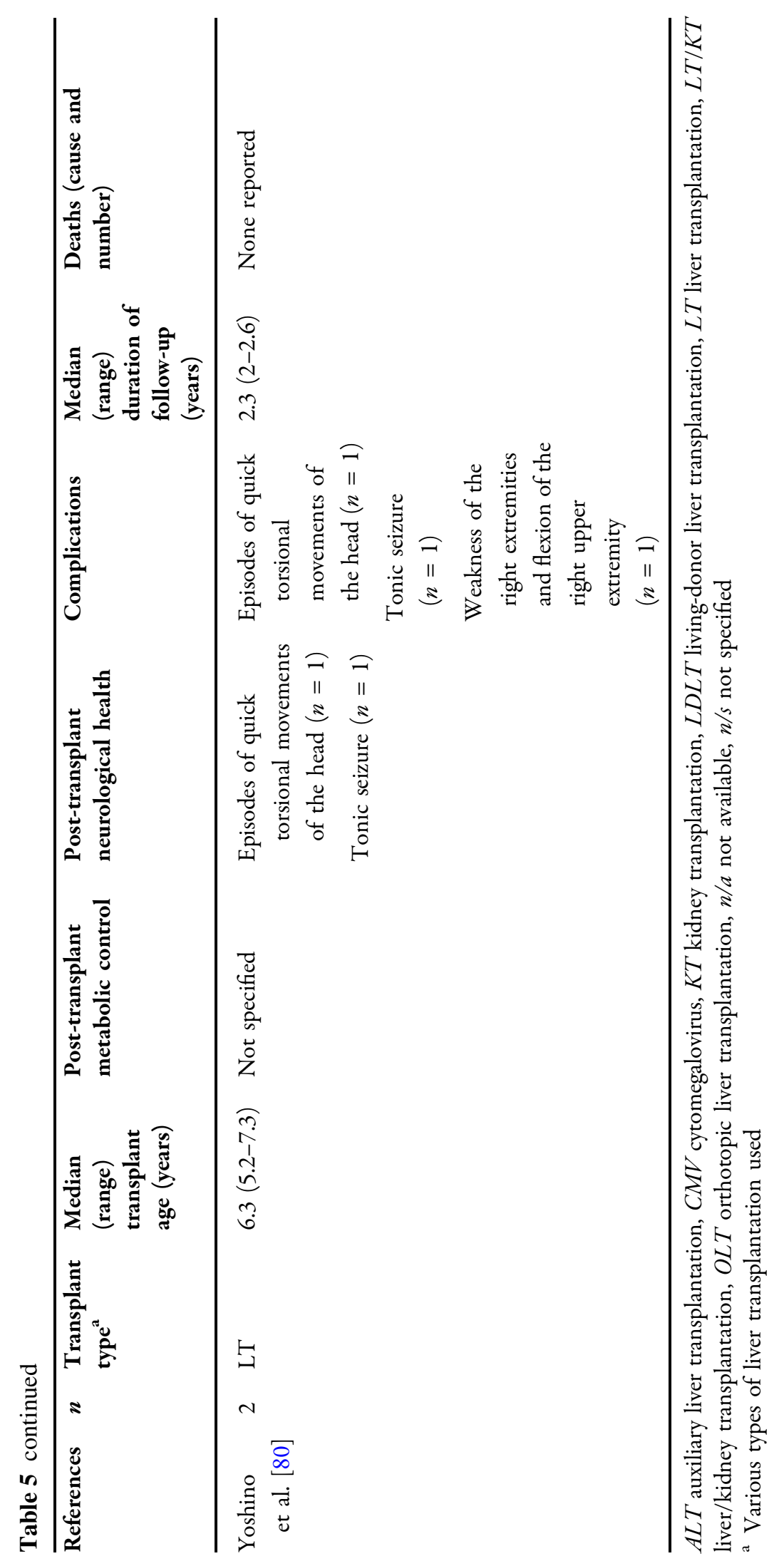




\section{REFERENCES}

1. Baumgartner MR, Hörster F, Dionisi-Vici C, et al. Proposed guidelines for the diagnosis and management of methylmalonic and propionic acidemia. Orphanet J Rare Dis. 2014;9:130.

2. Kim IK, Niemi AK, Krueger C, et al. Liver transplantation for urea cycle disorders in pediatric patients: a single-center experience. Pediatr Transpl. 2013;17:158-67.

3. Li M, Dick A, Montenovo M, Horslen S, Hansen R. Cost-effectiveness of liver transplantation in methylmalonic and propionic acidemias. Liver Transpl. 2015;21:1208-18.

4. Fabuioli J, Daina E, D'Antiga L, et al. Monogenic disease that can be cured by liver transplantation. J Hepatol. 2013;59:595-612.

5. Shneider BL. Pediatric liver transplantation in metabolic disease: clinical decision making. Pediatr Transpl. 2002;6:25-9.

6. Mazariegos G, Shneider B, Burton B, et al. Liver transplantation for pediatric metabolic disease. Mol Genet Metab. 2014;111:418-27.

7. Alvarez-Elias AC, Williams A, Hébert D. Kidney transplantation after liver transplantation in a patient with propionic acidemia: management challenges. Blood Purif. 2018;45:302-3.

8. Arrizza C, De Gottardi A, Foglia E, et al. Reversal of cardiomyopathy in propionic acidemia after liver transplantation: a 10-year follow-up. Transpl Int. 2015;28:1447-500.

9. Barshes NR, Vanatta JM, Patel AJ, et al. Evaluation and management of patients with propionic acidemia undergoing liver transplantation: a comprehensive review. Pediatr Transpl. 2006;10:773-81.

10. Charbit-Henrion F, Lacaille F, McKiernan P, et al. Early and late complications after liver transplantation for propionic acidemia in children: a two centers study. Am J Transpl. 2015;15:786-91.

11. Critelli K, McKiernan P, Vockley J, et al. Liver transplantation for propionic acidemia and methylmalonic acidemia: perioperative management and clinical outcomes. Liver Transpl. 2018;24: 1260-70.

12. Kasahara M, Sakamoto S, Kanazawa H, et al. Livingdonor liver transplantation for propionic acidemia. Pediatr Transpl. 2012;16:230-4.

13. Kasahara M, Sakamoto S, Horikawa R, et al. Living donor liver transplantation for pediatric patients with metabolic disorders: the Japanese multicenter registry. Pediatr Transpl. 2014;18:6-15.

14. Kayler LK, Merion RM, Lee S, et al. Long-term survival after liver transplantation in children with metabolic disorders. Pediatr Transpl. 2002;6: 295-300.

15. Lam C, Desviat LR, Perez-Cerdá C, et al. 45-Year-old female with propionic acidemia, renal failure, and premature ovarian failure; late complications of propionic acidemia? Mol Genet Metab. 2011;103: 338-40.

16. Moguilevitch M, Delphin E. Domino liver transplantation from a child with propionic acidemia to a child with idiopathic fulminant hepatic failure. Case Rep Transpl. 2018;2018:1897495.

17. Morioka D, Kasahara M, Takada Y, et al. Living donor liver transplantation for pediatric patients with inheritable metabolic disorders. Am J Transpl. 2005;5:2754-63.

18. Nagao M, Tanaka $T$, Morii $M$, et al. Improved neurologic prognosis for a patient with propionic acidemia who received early living donor liver transplantation. Mol Genet Metab. 2013;108:25-9.

19. Quintero J, Molera C, Juamperez J, et al. The role of liver transplantation in propionic acidemia. Liver Transpl. 2018;24:1736-45.

20. Rammohan A, Gunasekaran V, Reddy MS, Rela M. The role of liver transplantation in propionic acidemia. Liver Transpl. 2019;25:176-7.

21. Rela M, Battula N, Madanur M, et al. Auxiliary liver transplantation for propionic acidemia: a 10-year follow-up. Am J Transpl. 2007;7:2200-3.

22. Romano S, Valayannopoulos V, Touati G, et al. Cardiomyopathies in propionic aciduria are reversible after liver transplantation. J Pediatr. 2010;156: 128-34.

23. Schlenzig JS, Poggi-Travert F, Laurent J, et al. Liver transplantation in two cases of propionic acidaemia. J Inher Metab Dis. 1995;18:448-61.

24. Shanmugam NP, Valamparampil JJ, Srinivas Reddy $\mathrm{M}$, et al. Auxiliary partial orthotopic liver transplantation for monogenic metabolic liver diseases: single-centre experience. JIMD Rep. 2019;45:29-36.

25. Vara R, Turner C, Mundy H, et al. Liver transplantation for propionic acidemia in children. Liver Transpl. 2011;17:661-7.

26. Yorifuji T, Kawai M, Mamada M, et al. Living-donor liver transplantation for propionic acidaemia. J Inherit Metab Dis. 2004;27:205-10. 
27. Brassier A, Boyer O, Valayannopoulos V, et al. Renal transplantation in 4 patients with methylmalonic aciduria: a cell therapy for metabolic disease. Mol Genet Metab. 2013;110:106-10.

28. Chen PW, Hwu WL, Ho MC, et al. Stabilization of blood methylmalonic acid level in methylmalonic acidemia after liver transplantation. Pediatr Transpl. 2010;14:337-41.

29. Clothier JC, Chakrapani A, Preece MA, et al. Renal transplantation in a boy with methylmalonic acidaemia. J Inherit Metab Dis. 2011;34:695-700.

30. Duclaux-Loras R, Bacchetta J, Berthiller J, et al. Pediatric combined liver-kidney transplantation: a single-center experience of 18 cases. Pediatr Nephrol. 2016;31:1517-29.

31. Hirotsu A, Kusudo E, Mori N, et al. Successful perioperative management of living-donor liver transplantation for a patient with severe methylmalonic acidemia: a case report. JA Clin Rep. 2018;4:83.

32. Khanna A, Gish R, Winter SC, et al. Successful domino liver transplantation from a patient with methylmalonic acidemia. JIMD Rep. 2016;25: 87-94.

33. Lubrano R, Elli M, Rossi M, et al. Renal transplant in methylmalonic acidemia: could it be the best option? Report on a case at 10 years and review of the literature. Pediatr Nephrol. 2007;22:1209-14.

34. Lubrano R, Perez B, Elli M. Methylmalonic acidemia and kidney transplantation. Pediatr Nephrol. 2013;28:2067-8.

35. McGuire PJ, Lim-Melia E, Diaz GA, et al. Combined liver-kidney transplant for the management of methylmalonic aciduria: a case report and review of the literature. Mol Genet Metab. 2008;93:22-9.

36. Morioka D, Kasahara M, Horikawa R, et al. Efficacy of living donor liver transplantation for patients with methylmalonic acidemia. Am J Transpl. 2007;7:2782-7.

37. Nagarajan S, Enns GM, Millan MT, et al. Management of methylmalonic acidaemia by combined liver-kidney transplantation. J Inherit Metab Dis. 2005;28:517-24.

38. Niemi AK, Kim IK, Krueger CE, et al. Treatment of methylmalonic acidemia by liver or combined liver-kidney transplantation. J Pediatr. 2015;166(1455-61):e1.

39. Nyhan WL, Gargus JJ, Boyle K, Selby R, Koch R. Progressive neurologic disability in methylmalonic acidemia despite transplantation of the liver. Eur J Pediatr. 2002;161:377-9.
40. Sakamoto R, Nakamura K, Kido J, et al. Improvement in the prognosis and development of patients with methylmalonic acidemia after living donor liver transplant. Pediatr Transpl. 2016;20:1081-6.

41. Spada M, Calvo PL, Brunati A, et al. Early liver transplantation for neonatal-onset methylmalonic acidemia. Pediatrics. 2015;136:e252-e256256.

42. Stevenson T, Millan MT, Wayman K, et al. Longterm outcome following pediatric liver transplantation for metabolic disorders. Pediatr Transpl. 2010;14:268-75.

43. Edwards EB, Roberts JP, McBride MA, et al. The effect of the volume of procedures at transplantation centers on mortality after liver transplantation. N Engl J Med. 1999;341:2049-53.

44. Nichols TJ, Price MB, Villarreal JA, et al. Most pediatric transplant centers are low volume, adultfocused, and in proximity to higher volume pediatric centers. J Pediatri Surg. 2019;5:6. https://doi. org/10.1016/j.jpedsurg.2019.10.019.

45. Rana A, Pallister Z, Halazun K, et al. Pediatric liver transplant center volume and the likelihood of transplantation. Pediatrics. 2015;136:e99-e107.

46. Tracy ET, Bennett KM, Danko ME, et al. Low volume is associated with worse patient outcomes for pediatric liver transplant centers. J Pediatri Surg. 2010;45:108-13.

47. Corno V, Lucianetti A, Stroppa P, et al. Pediatric liver-kidney transplantation: a single center experience. Transpl Int. 2011;24(Suppl 2):318 (Abstract P-370).

48. Martinelli D, Liccardo D, Catesini G, et al. Persistent CSF biochemical abnormalities in transplanted patients with methylmalonic aciduria: a longitudinal study. J Inherit Metab Dis. 2018;41(Suppl 1): S126 (Abstract P-190).

49. Van Calcar SC, Harding CO, Lyne P, et al. Renal transplantation in a patient with methylmalonic acidaemia. J Inherit Metab Dis. 1998;21:729-37.

50. Abdullah AA, Moustafa MM, Simon RB. Anticoagulation and antiplatelets as prophylaxis for hepatic artery thrombosis after liver transplantation. World J Hepatol. 2015;7:1238-43.

51. Ma N, Song Z, Dong C, et al. Risk factors of hepatic artery thrombosis in pediatric deceased donor liver transplantation. Pediatr Surg Int. 2019;35:853-9.

52. Leonard JV, Walter JH, McKiernan PJ. The management of organic acidaemias: the role of transplantation. J Inherit Metab Dis. 2001;24:309-11. 
53. Singh N, Bonham A, Fukui M. Immunosuppressiveassociated leukoencephalopathy in organ transplant recipients. Transplantation. 2000;69:467-72.

54. Williams M, Dionisi-Vici C, Molema F. Organ transplantation in individuals with urea cycle disorders and classic organic acidurias. In: Presentation at 8th Annual E-IMD Members Meeting, 13th November 2018. Brussels.

55. Celik N, Soltys K, Bond G, et al. Liver transplantation for propionic acidemia: a review of the United States Scientific Registry for Transplant Recipients (SRTR) and non-US case series. Am J Transpl. 2016;16(suppl 3):766 (Abstract D210).

56. Celik N, Ganoza A, Bond G, et al. Allograft domino liver transplantation for selected metabolic disorders. Pediatr Transpl. 2017;21(Suppl 1):3 (Abstract 202.4).

57. Curnock R, Vara R, Hadzic N, Heaton N, Vilca-Melendez $\mathrm{H}$, Dhawan A. Liver transplantation in propionic acidaemia: a single centre experience in the UK. J Inherit Metab Dis. 2018;41(Suppl 1):S124 (Abstract P-185).

58. Duckworth C, Yazigi N. Hospitalizations, dietary treatment, and metabolic markers in propionic acidemia patients pre-and post-liver transplant. Mol Genet Metab. 2018;123:227-8.

59. Longo N. Effect of liver transplantation on hyperammonemia and metabolic control in propionic acidemia. J Inborn Errors Metab Screen. 2017;5:185 (Abstract 410).

60. Molera C, Quintero Bernabeu J, Juamperez Goni J, et al. Liver transplantation in propionic acidemia. J Pediatr Gastroenterol Nutr. 2017;64(Suppl 1):723 (Abstract H-P-065).

61. Nassogne M, Vincent M, Reding R, et al. Late-onset cardiac failure after liver transplantation in one patient with propionic acidemia. J Inherit Metab Dis. 2015;38(Suppl 1):S161-S162162.

62. Nguyen NT, Harring TR, O'Mahony C, et al. Propionic acidemia and orthotopic liver transplantation: the UNOS experience. Am J Transpl. 2011;11(Suppl 2):496-7.

63. Ovchinsky N, Cunningham RM, Kogan-Liberman $\mathrm{D}$, et al. Expanding the utilization of metabolic livers for domino transplantation: successful domino liver transplant from a patient with propionic acidemia. Hepatology. 2016;64(Suppl 1): 700A-701A (abstract 1399).

64. Quintero J, Molera C, Juemparez J, et al. The role of liver transplantation for propionic acidemia in children. Pediatric Transpl. 2017;21(suppl 1):50 (Abstract P129).

65. Reddy M, Shanmugham N, Varghese J, et al. Auxiliary partial orthotopic liver transplantation (APOLT): a safe and effective alternative to orthotopic liver transplantation for patients with acute liver failure and non-cirrhotic metabolic liver disease. Transplantation. 2016;100(Suppl 1):S6-47 (Abstract 325.8).

66. Valamparampil JJ, et al. Preserving the native liver for future; auxiliary partial orthotopic liver transplantation (APOLT) for monogenic metabolic liver disease (MLD). Hepatol Int. 2018;12(2):S644-S645.

67. Vara R, Turner C, Champion M, et al. Liver transplantation for propionic acidemia in children. J Pediatr Gastroenterol Nutr. 2010;50(suppl 2): E163-E164 (Abstract PO-H-355).

68. Vara R, Mundy $\mathrm{H}$, Champion $\mathrm{M}$, et al. Medium term outcome of liver transplantation for children with propionic acidaemia. Hepatology. 2016;64(suppl 1):335A-6A (Abstract 676).

69. Walker PLC, Miller O, Vara R. Role of cardiac monitoring in patients with propionic acidaemia following liver transplantation: a retrospective review. J Inherit Metab Dis. 2014;37(Suppl 1):S89 (Abstract P-172).

70. Almeida J, Garcia P, Ferreira F, Faria A, Goncalves I, Diogo L. Improvement in neuropsychological outcomes of a child with methylmalonic acidemia after liver transplantation. J Inherit Metab Dis. 2018;41(Supplement 1):S128 (Abstract P-196).

71. Barshop BA, Nyhan WL, Khanna A. Domino liver transplantation in methylmalonic acidemia. J Inherit Metab Dis. 2012;35(Suppl 1):S9 (Abstract O-026).

72. Boyer O, Krug P, Guest G, Valayannopoulos V, Niaudet P. Methylmalonic acidemia: a new indication for preemptive renal transplantation? Pediatr Nephrol. 2010;25:1815 (Abstract 100).

73. Fukuda A, Kasahara M, Sakamoto S, et al. Evaluation of living donor liver transplantation for patients with methylmalonic acidemia. J Pediatr Gastroenterol Nutr. 2011;52(suppl 1):E201.

74. Jiang Y, Sun L. Perioperative characteristics of liver transplantation for methylmalonic acidemia and management experience. Transplant. 2018;102(suppl):317-8 (Abstract LB P-041).

75. Matsumoto I, Kenmochi T, Maruyama M, et al. Renal transplantation for chronic renal failure in methylmalonic acidemia: a case report. Transplantation. 2012;94(10S):859 (Abstract 795). 
76. Nakajima Y, Ito T, Ichiki S, et al. Case study of methylmalonic acidemia presenting with acute encephalopathy associated with basal nuclei lesions 20 months after liver transplantation from a living donor. J Inherit Metab Dis. 2010;33(Suppl 1):S54 (Abstract 131-P).

77. Shenoy M, Jameson E, Webb N. Single centre experience of isolated kidney transplantation in methylmalonic aciduria. Pediatr Nephrol. 2015;30(9):1708 (Abstract P-431).

78. Sissaoui S, Brassier A, Chardot C, et al. Early liver transplantation or combined liver-kidney transplantation: what is the best solution for methylmalonic acidemia? J Pediatr Gastroenterol Nutr. 2017;64(suppl 1):648 (Abstract H-eP-030).

79. Yamamoto $\mathrm{S}$, et al. Kidney transplantation in a 26-year-old Japanese male with methylmalonic aciduria presenting end stage renal failure (Second Report). J Inherit Metab Dis. 2012;35(Suppl 1):S64.

80. Yoshino M, Oohira T, Watanabe Y, Okada J. Neurological deterioration in two patients with methylmalonic aciduria following liver transplantation and subsequent relaxation of natural protein intake. J Inherit Metab Dis. 2010;1(33):S46. 